\title{
CONTAMINAÇÃO DOS RECURSOS HÍDRICOS E GESTÃO INTEGRADA NO LITORAL NORTE DO RIO GRANDE DO SUL ${ }^{1}$
}

\author{
Juliane Beatriz Lissner ${ }^{2}$ \\ Nelson Luiz Sambaqui Gruber. ${ }^{3}$
}

\section{Resumo}

O trabalho a seguir apresenta a importância dos recursos hídricos costeiros e sua gestão através da demonstração dos problemas mais encontrados nestas áreas relacionando-os com a qualidade da água dos rios e lagoas. Os problemas mais comuns observados no Litoral Norte do estado do Rio Grande do Sul foram ocupações inadequadas em torno dos rios e lagoas e o lançamento de esgoto diretamente nos corpos de água. Em relação a apresentação de soluções e gestão dos recursos hídricos a dificuldade tem sido relacionar os dados do enquadramento da qualidade da água, pois o cruzamento com os dados da legislação vigente não são compatíveis, bem como a dificuldade da gestão integrada que esteja de acordo com estas leis e que também atendam aos requisitos de desenvolvimento da região e das comunidades locais, buscando a preservação do meio ambiente.

Palavras-chave: recursos hídricos, gestão, contaminação.

\section{Abstract}

The work following present the importance of coastal hydric recourses and their management through the demonstration of the common problems observed in this areas to relate with the quality water from rivers and lagoons. The problem have been observed in the North Coastland of the Rio Grande do Sul State by the inadequate occupation around the rivers and lagoons and by drainage thrown directly in the water course. Relating to presentation of solution and management of the hydric recourses the difficult has been to relate results of

\footnotetext{
${ }^{1}$ Trabalho de pesquisa realizado durante disciplina de Gerenciamento Costeiro e base para a dissertação de mestrado.

2 Mestranda Juliane Beatriz Lissner - Programa de Pós-Gradução em Geografia (PPGEA) - Instituto de Geociências - Universidade Federal do Rio Grande do Sul (UFRGS). E-mail: jujubl85@yahoo.com.br

${ }^{3}$ Prof. Dr. Nelson Luiz Sambaqui Gruber - Programa de Pós-Graduação em Geografia (PPGEA) - Instituto de Geociências - Universidade Federal do Rio Grande do Sul (UFRGS). E-mail: nelson.gruber@ufrgs.br
} 
classification water quality, because the crossing results with the valid legislation is don't compatible, as well as the difficult of the integration management to be in accordance with the law and attend also requisites of the region development and local community, researching to preserve the environment.

Key-words: hydric recourses, management, contamination.

\section{Introdução}

Preservar e distribuir recursos de água é um desafio importante para a sociedade. Os ecossistemas aquáticos são importantes indicadores da quantidade e da qualidade da água. Conforme Braga et al (2005) para realizarem suas funções, os ecossistemas aquáticos requerem proteção e gestão, sem os quais geram sérias consequências ambientais, sociais e também econômicas. Desta forma, é evidente que para se alcançar uma gestão sustentável dos recursos hídricos necessita-se de uma gestão integrada.

Conforme a Fepam (2000) o Litoral Norte do estado do Rio Grande do Sul é uma região riquíssima sob o ponto de vista ambiental, constituído por um cordão de lagoas litorâneas, banhados, barreiras de dunas e contrafortes da Serra Geral, sendo seus ecossistemas frágeis e raros. Assim, devido ao aumento da ocupação nos municípios situados na zona litorânea, os recursos hídricos costeiros vêm sofrendo diversas intervenções humanas, tais intervenções tem como consequência sérios conflitos em torno do uso da água, saneamento básico e agricultura.

De acordo com a Fepam (2000) a ocupação mais intensiva da região iniciou-se com a chegada dos açorianos vindos de Santa Catarina. A região era ocupada originalmente por fazendas de criação de gado. A partir da década de 40, foram instalados pequenos aglomerados de casas para abrigar as famílias vindas da capital e de outras regiões durante os meses de verão. Desta forma, o veraneio passou a ser o principal uso dado a planície costeira.

A economia da região passou a ser sustentada principalmente pelos serviços de apoio ao veranista, construção civil e pequena indústria moveleira e de artes, o que impulsionou a expansão dos balneários.

No entanto, conforme a Fepam (2000) as deficiências de infraestrutura e serviços de saneamento básico e ausência de diretrizes para a ocupação da região acarretou em impactos nos ecossistemas e pode provocar empecilhos para a plena prática do veraneio.

O crescimento das cidades de forma desordenada acarreta diversos problemas, tais como a ocupação de áreas de preservação e áreas inundáveis que muitas vezes são aterradas; ocupação de áreas de dunas; abastecimento de água provinda de poços irregulares que são 
susceptíveis a contaminação; e poluição das águas superficiais e subterrâneas através de despejos de esgoto sem tratamento.

Na região litorânea onde se encontram as lagoas há também uma agricultura bastante desenvolvida, baseada principalmente em plantações de arroz irrigado, o qual necessita de grande abastecimento de água. As lavouras de arroz utilizam também fertilizantes e agrotóxicos que podem contaminar as águas superficiais, tais como as lagoas da região.

\section{Área de estudo}

O Litoral Norte do Rio Grande do Sul abrange 19 municípios, sendo estes: Arroio do Sal, Capão da Canoa, Cidreira, Dom Pedro de Alcântara, Imbé, Itati, Mampituba, Maquiné, Morrinhos do Sul, Osório, Pinhal, Santo Antônio da Patrulha, São Francisco de Paula, Terra de Areia, Torres, Tramandaí, Três Cachoeiras, Três Forquilhas e Xangrilá, conforme a delimitação definida pelo Programa de Gerenciamento Costeiro (GERCO).

O Litoral Norte é delimitado pelo rio Mampituba ao norte e pelo município Balneário Pinhal ao sul, a leste pelo oceano Atlântico e a oeste é delimitado conforme a sua formação geológica, relevo, bacias hidrográficas e limites políticos, estendendo-se até o município de São Francisco de Paula, área esta que sofre influências marítimas. A área compreende 16 lagoas, 4 rios e os estuários de Tramandaí e de Torres que são representativos dos diversos tipos de ambientes da região. Os municípios integrantes da região do Litoral Norte do Rio Grande do Sul encontram-se delimitados conforme definição do GERCO, na Figura 1.

A Planície Costeira do Rio Grande do Sul é uma vasta área de terras baixas (33.000 $\mathrm{Km}^{2}$ ) e em sua maior parte ocupada por um enorme sistema de lagoas costeiras. Constitui-se em uma região de idade geológica recente (cerca de 5.000 a.C.), cujos ecossistemas apresentam características raras e frágeis, mostrando uma seqüência de ambientes de especial valor paisagístico (Pereira e Shäfer, 2007). 


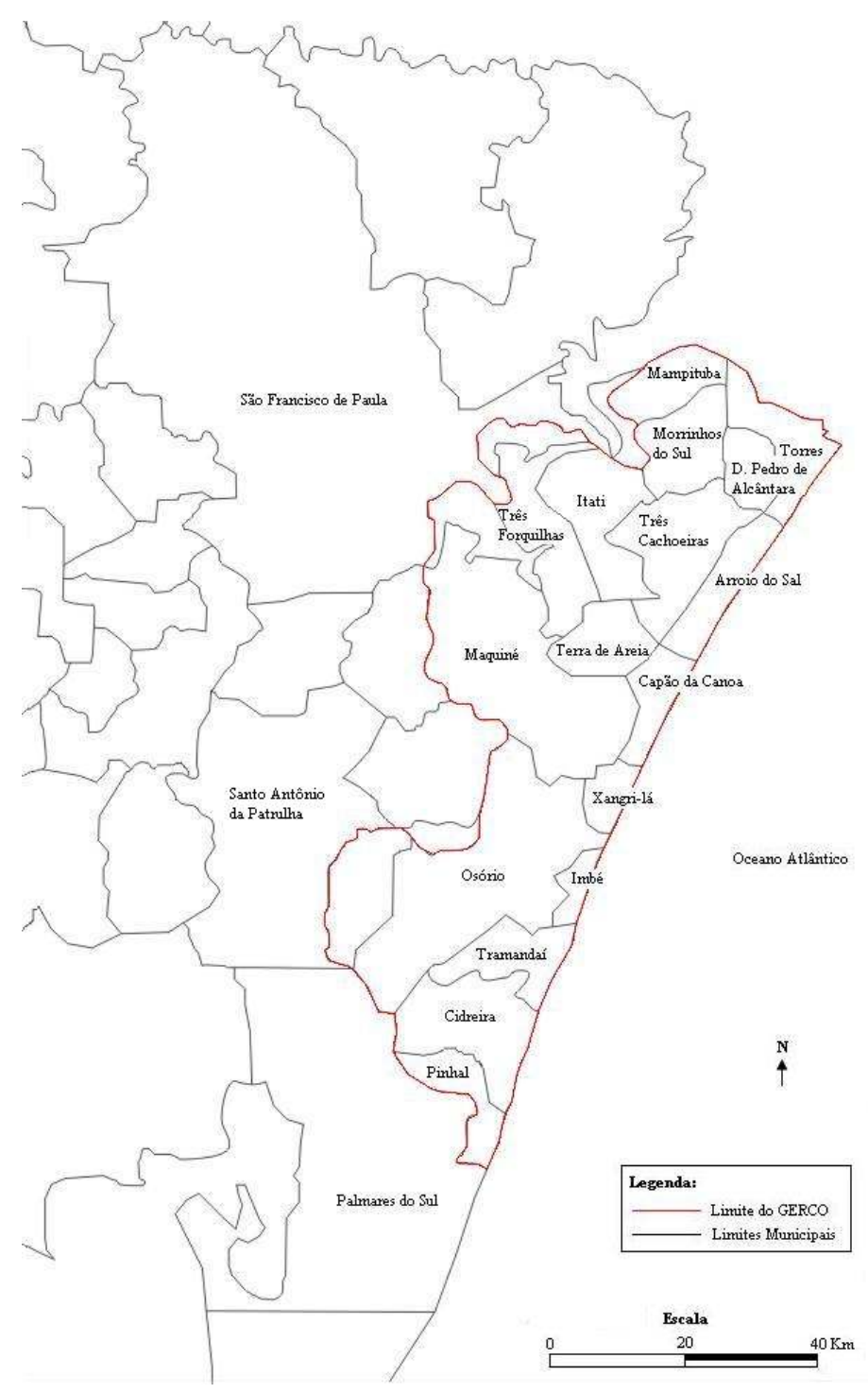

Figura 1: Municípios do Litoral Norte Org.: Lissner, J. B. (2009)

A Província Costeira do Rio Grande do Sul é constituída em parte, pela Bacia de Pelotas (Villwock e Tomazelli, 2007), apoiada sobre um embasamento composto pelo complexo cristalino pré-cambriano e pelas sequências sedimentares e vulcânicas, paleozoicas e mesozoicas da Bacia do Paraná, a Bacia de Pelotas teve sua origem relacionada a movimentos de tectônica. A ocorrência do sistema de lagoas costeiras da região tem sua origem em processos de regressão e transgressão marinha datadas do pleistoceno e holoceno, que caracterizaram a formação da planície costeira através do sistema Barreira/Laguna, podendo ser observado a ocorrência das formações da Barreira I, Barreira II, Barreira III e Barreira IV. 
A sequência de lagoas encontra-se paralela a linha oceânica, no entanto, algumas delas são mais interiores, como a Lagoa dos Barros e outras na região de Osório.

As lagoas costeiras possuem normalmente contorno cordiforme em função dos mecanismos eólicos, que sopram em direção predominante de NE-SW; os corpos de água geralmente são rasos, o que facilita a ação dos ventos provocando modificações dinâmicas em curtos períodos de tempo. Os ventos atuantes na região influenciam na dinâmica e morfologia do sistema lagunar, bem como na distribuição das comunidades vegetais e animais. As lagoas de água doce da região destacam-se por seu uso para recreação, abastecimento público e irrigação.

O clima do litoral do Rio Grande do Sul pode ser caracterizado conforme Nimer (1977, apud Villwock e Tomazelli, 2007) como sendo de clima mesotérmico brando, super úmido sem estação seca. A temperatura média anual oscila entre 16 e $20^{\circ} \mathrm{C}$, e a precipitação pluviométrica anual varia entre 1.000 e $1.500 \mathrm{~mm}$.

\section{Metodologia}

O levantamento de fontes primárias abrangeu observações e registros fotográficos em campo, realizado nos dias 18 e 19 de maio de 2009. O levantamento de dados secundários contemplou pesquisa bibliográfica e cartográfica.

\section{Qualidade e enquadramento da água das lagoas costeiras}

O enquadramento das águas é um termo legal para designar o processo de planejamento do uso da água. Esse planejamento serve para definir as metas de proteção ambiental e usos prioritários que queremos fazer dos lagos e rios.

Os usos prioritários podem ser definidos como: abastecimento doméstico, proteção das comunidades aquáticas e recreação de contato primário. $\mathrm{O}$ uso da água para irrigação das lavouras apesar de bastante significativo e necessário, muitas vezes é conflitante com os usos prioritários e com a fragilidade dos ecossistemas locais.

$\mathrm{Na}$ Figura 2 estão representadas as lagoas do Litoral Norte e seu respectivo enquadramento quanto a qualidade da água conforme classificação realizada pela Fepam. Podemos observar que a maior parte das águas doces enquadram-se nas classes 1 e 2 e somente o estuário do Tramandaí encontra-se na classe 3, sendo indício de alta poluição ocasionada pelos centros urbanos próximos. Não existem águas enquadradas na classe especial, que são águas de ótima qualidade. As lagoas de água salobra encontram-se enquadradas na classe B (Figura 2). 


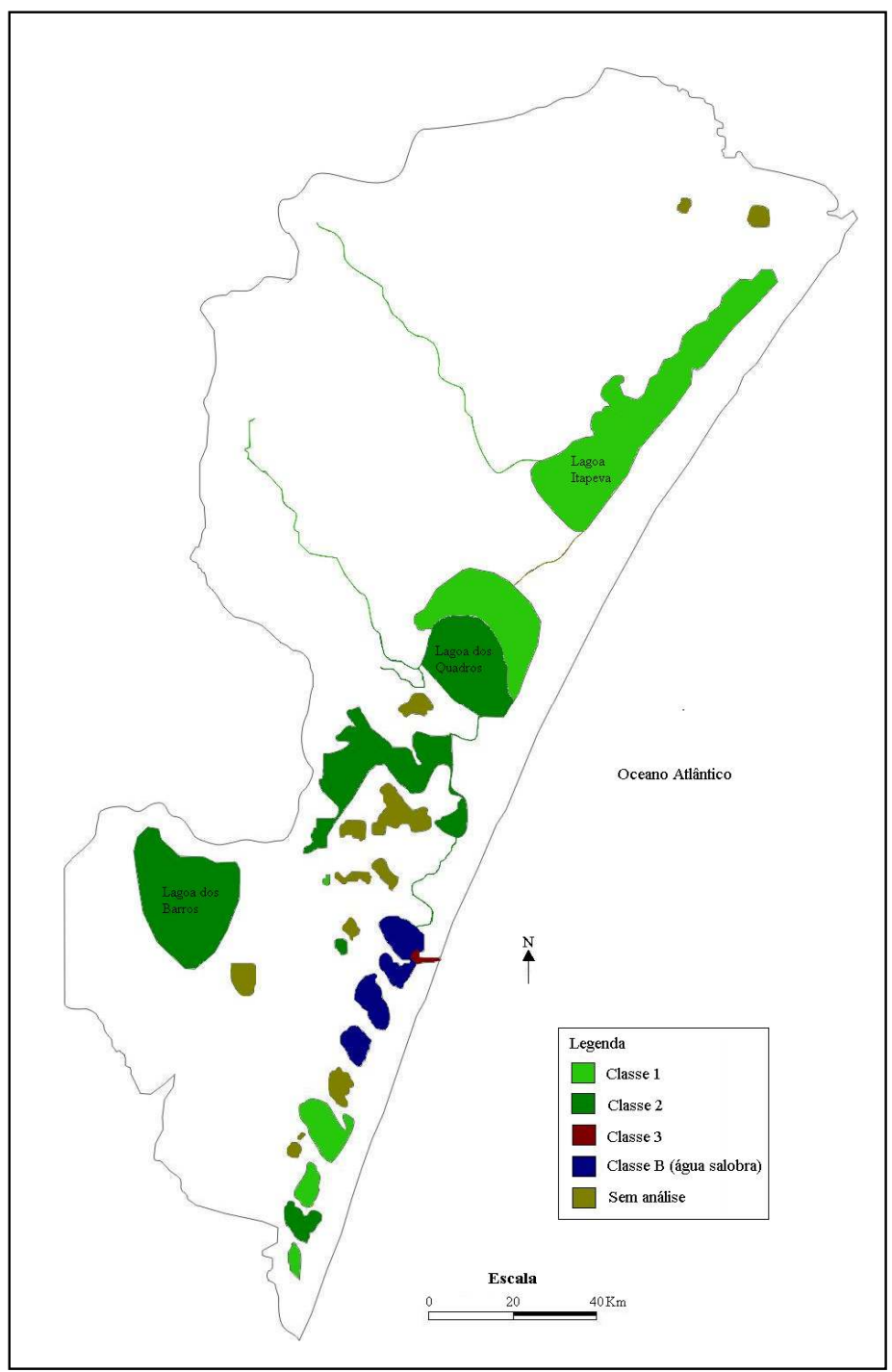

Figura 2: Enquadramento da qualidade da água das lagoas Org.: Lissner, J. B. (2009)

Assim, as águas disponíveis na região do litoral norte já se encontram em sua maior parte contaminadas por despejos domésticos ou mesmo por agrotóxicos e pesticidas provenientes da agricultura local, o que comprova que os ecossistemas aquáticos sofrem constantemente intervenções antrópicas.

Algumas lagoas ainda não possuem uma análise da qualidade de suas águas, assim, de acordo com a Resolução do CONAMA de março de 2005, as águas que ainda não foram classificadas devem ser enquadradas na classe 2.

Porém, os dados apresentados na Figura 2 relativo ao enquadramento das águas quanto a sua qualidade foi realizada pela Fepam no ano de 2000, sendo que a qualidade da água 
destas lagoas pode ter sofrido diversas modificações nos últimos anos devido ao crescimento relativamente rápido da área urbana, o que pode gerar uma maior contaminação das águas pelos esgotos domésticos e consequentemente baixar o índice de qualidade das águas.

Conforme estudos realizados pela Fepam (2000), os níveis de concentração de oxigênio estão acima de $6 \mathrm{mg} / \mathrm{L}$ na maioria dos corpos de água da Classe 1 da região representando um bom índice, exceto no rio Mampituba, na lagoa dos Barros, Marcelino Ramos, laguna Tramandaí e lagoa Armazém que apresentam concentrações de oxigênio abaixo deste índice.

A lagoa Marcelino Ramos destaca-se pela presença de matéria orgânica oriunda de esgotos cloacais do município de Osório, apresentando concentrações de Demanda Bioquímica de Oxigênio (DBO) relativos a Classe 3 (DBO 5 dias a $20^{\circ} \mathrm{C}$ apresentando 10 $\mathrm{mg} / \mathrm{L} \mathrm{O} 2$ ). O rio Maquiné, próximo ao arroio Pinheiro apresenta concentrações de Classe 2, isto é, DBO 5 dias a $20^{\circ} \mathrm{C}$ de até $5 \mathrm{mg} / \mathrm{L}$ O2, o rio Mampituba também apresenta concentrações de Classe 2 mas com menor freqüência.

As maiores concentrações de Coliformes Fecais são encontradas no rio Mampituba, em especial na foz; na lagoa Itapeva e no estuário do rio Tramandaí. As causas mais prováveis são os esgotos cloacais dos municípios de Torres, Osório, Tramandaí e Imbé.

Os recursos hídricos localizados mais ao sul desta região, tais como as lagoas Fortaleza, Gentil, Rondinha e Cerquinha apresentam melhores condições de qualidade ambiental, resultado este relacionado provavelmente às baixas taxas de ocupação antrópica no entorno destas.

\section{Resoluções do Conselho Nacional do Meio Ambiente - CONAMA}

De acordo com o Conselho Nacional do Meio Ambiente - Conama, Resolução No 357 de 17 de março de 2005, dispõe sobre a classificação dos corpos de água e diretrizes ambientais para seu enquadramento.

Desta forma, as águas doces são águas com salinidade igual ou inferior a $0,5 \%_{0}$. E as águas salobras com salinidade superior a $0,5 \%$ o inferior a $30 \%$.

Os parâmetros geralmente utilizados para definir a qualidade da água dos corpos hídricos são substâncias ou indicadores representativos da qualidade da água. No Rio Grande do Sul estes parâmetros são definidos pela Fepam, Corsan e Dmae, analisando os itens da tabela 1 para o cálculo do Índice da Qualidade da Água (IQA).

O Índice da Qualidade da Água é realizado através da coleta de amostras de água do local de estudo e analisadas por laboratórios especializados com a finalidade de se obter os 
valores dos parâmetros relacionados na tabela abaixo. Assim, cada parâmetro possui um peso percentual e, após utilizado o cálculo para definir o IQA, resultará em um valor de 0 a 100 classificando a água como ótima, boa, regular, ruim ou péssima. Na tabela 1 podemos ver os pesos relativos a cada parâmetro conforme definido pela Fepam, Corsan e Dmae:

\begin{tabular}{l|c}
\hline Parâmetros IQA & Peso (wi) \\
\hline Oxigênio Dis.(OD) & 0,19 \\
\hline Coliformes Fecais & 0,17 \\
\hline PH & 0,13 \\
\hline DBO $_{5}$ & 0,11 \\
\hline Nitrogênio Total & 0,11 \\
\hline Fósforo Total & 0,11 \\
\hline Turbidez & 0,09 \\
\hline Sólidos Totais & 0,09 \\
\hline
\end{tabular}

Tabela 1 - Parâmetros analisados pelo IQA Org.: Lissner, J. B. (2009)

No entanto, a classificação da qualidade da água das lagoas conforme o mapa elaborado pela Fepam (Figura 2) não indica quais foram os parâmetros analisados, o que dificulta a interpretação em relação a real qualidade da água, normalmente são analisados os parâmetros mais importantes relativos ao consumo humano de água.

De certa forma o enquadramento das águas sempre busca estabelecer uma meta ou objetivo de qualidade da água a ser seguido ou mantido obrigatoriamente em um segmento de corpo de água, de acordo com a finalidade de uso desta.

De acordo com o CONAMA (2005) as águas de classe 1 e classe 2, enquadramento da maioria das águas das lagoas doces do Litoral Norte do estado, podem ser utilizadas para os fins a seguir.

As águas de classe 1 podem ser utilizadas para:

- o abastecimento para o consumo humano, após tratamento simples;

- à proteção de comunidades aquáticas;

- à recreação de contato primário;

- à irrigação de hortaliças que são consumidas cruas e de frutas que se desenvolvem rentes ao solo e que sejam ingeridas cruas sem remoção da película protetora. 
As águas de classe 2 podem ser utilizadas para:

- o abastecimento para o consumo humano, após tratamento convencional;

- à proteção de comunidades aquáticas;

- à recreação de contato primário;

- à irrigação de hortaliças, plantas frutíferas e de parques, jardins, campos de esporte e lazer, com os quais o público possa vir a ter contato direto.

- à aquicultura e à atividade de pesca.

Quanto maior for a classe, maior será a restrição de uso da água e a qualidade será mais baixa.

As águas salobras, encontradas nas lagoas mais próximas do mar, também são classificadas conforme os itens e destinadas a certos usos. As águas da classe B, por exemplo, são águas destinadas apenas para a pesca amadora e à recreação de contato secundário.

A utilização de águas de melhor qualidade para fins de menor exigência não possui restrições desde que tais usos não prejudiquem a qualidade estabelecida para essas águas.

\section{Código Estadual do Meio Ambiente FEPAM}

De forma geral, o Código Estadual do Meio Ambiente dispõe que todos têm direito ao meio ambiente equilibrado, bem de uso comum e essencial a vida, sendo que o Estado, o Município e os cidadãos têm o dever de defendê-lo, preservá-lo e conservá-lo para as gerações futuras. De acordo com a Fepam (2000) compete também ao Poder Público criar estratégias visando à proteção e a recuperação dos processos ecológicos essenciais para a vida.

Em conformidade com a Constituição Estadual, o gerenciamento das águas pelo Poder Público Estadual será levado a cabo pelo Sistema Estadual de Recursos Hídricos (SERH) seguindo preceitos tais como:

- proteção das águas superficiais e subterrâneas contra ações que possam comprometer o seu uso sustentável e a melhoria gradual da qualidade da água;

- preservação e conservação dos ecossistemas aquáticos;

- utilização racional dos recursos hídricos e o abastecimento das populações humanas;

- participação de toda comunidade, usuários, órgãos públicos, organizações educacionais e científicas em colegiados de poder decisório na gestão dos recursos hídricos, entre outros.

Nos processos de outorga ou licenciamento de utilização dos recursos hídricos deverão comprovar que a utilização não causará poluição em níveis superiores estipulados pela 
legislação e manterá os níveis históricos médios para a manutenção da vida aquática e o abastecimento público, conforme Fepam (2000).

Assim, a legislação dispõe sobre a preservação e conservação da qualidade das águas, restringindo o descarte de resíduos que poderão conferir ao corpo de água receptor características de alteração de comportamento, reprodução ou fisiologia da vida.

A utilização de redes de esgotos pluviais para o transporte e afastamento de esgotos sanitários somente é permitida mediante o licenciamento pelo órgão ambiental responsável cumprindo todas as ordens de tratamento do esgoto antes do seu lançamento no corpo de água.

A legislação ambiental estadual é uma das mais completas, pois abrange e dispõe sobre os impactos ambientais e regulamenta as ações que devem ser tomadas, porém, conforme a bibliografia consultada e através das observações realizadas em campo podemos observar que as leis nem sempre são cumpridas e respeitadas. Muitos órgãos públicos municipais do Litoral Norte não dispõem de tratamento adequado aos esgotos sanitários e acabam lançando a maior parte dos resíduos nos corpos de água "in natura".

\section{Os impasses sobre a utilização das lagoas costeiras}

As lagoas do litoral norte são administradas pelos municípios que fazem parte do litoral norte, porém, há casos onde ocorrem impasses sobre a questão do gerenciamento, como no caso da lagoa dos Barros que pertence aos municípios do litoral norte, porém encontra-se dentro da bacia e comitê do Litoral médio, pois está situada entre as Barreiras geológicas II e III.

O impasse na Lagoa dos Barros gira em torno da construção da Estação de Tratamento de Esgoto (ETE) pelo município de Osório nas margens da lagoa. No entanto, a lagoa dos Barros localiza-se em sua maior parte dentro dos limites do município de Santo Antônio da Patrulha, município este que não foi contatado antecipadamente sobre a construção da ETE.

Conforme as fontes consultadas, a construção da ETE foi autorizada e licenciada pela Fepam, órgão responsável que aprovou o projeto apresentado pela Corsan, declarando que a Lagoa dos Barros seria a melhor opção para a instalação da ETE em relação ao seu tamanho e a direção dos ventos que proporcionariam uma limpeza natural, e que seria a melhor opção para receber os efluentes tratados.

O município de Santo Antônio da Patrulha declarou não ser contra a construção da estação, no entanto, enfatiza que a obra está sendo construída no local errado, e quer a 
garantia de que a qualidade da água da lagoa dos Barros não seja prejudicada de forma alguma.

A justificativa em relação a não utilização das outras lagoas que se encontram no limite do município de Osório foi que as outras lagoas já estavam comprometidas pela contaminação. O impasse em torno da construção da ETE e do gerenciamento dos corpos hídricos da região demonstra que há vários interesses em torno da questão, sendo que a melhor opção seria a gestão integrada de forma a beneficiar a todos prejudicando ao mínimo o ecossistema aquático.

\section{Condições e padrões de lançamento de efluentes}

De acordo com a Resolução do CONAMA, No 357 de 17 de março de 2005, Capitulo IV, os efluentes de qualquer fonte poluidora somente poderão ser lançados, direta ou indiretamente, nos corpos hídricos após tratamento adequado conforme as condições e padrões exigidos na Resolução.

Desta forma, os órgãos tanto federais, estaduais como municipais deverão estabelecer através de normas específicas ou no licenciamento da atividade ou empreendimento, a carga poluidora máxima para o lançamento de substâncias poluidoras.

Não é permitido o lançamento dos chamados POPs (Poluentes Orgânicos Persistentes) nos recursos hídricos, e nem a disposição de efluentes no solo, mesmo que tratados, que oferecem risco de contaminação das águas tanto superficiais quanto subterrâneas. Também não é permitida a diluição do efluente antes de seu lançamento, como misturas de efluentes com águas de melhor qualidade.

Além destes requisitos, o órgão ambiental competente deverá observar quando a vazão estiver abaixo da referência, como em épocas de estiagem, poderá estabelecer restrições e medidas adicionais, de caráter excepcional e temporário.

Desta forma, os municípios situados na região que dependem do lançamento do seu esgoto nas águas superficiais locais devem procurar se adequar as normas de lançamento de efluentes determinados por lei assim como construir estações de tratamento de esgotos com a finalidade de evitar a contaminação das águas.

\section{Tratamento de esgoto dos municípios do Litoral Norte}

O abastecimento público de água e rede de esgoto da região é realizado, em sua maior parte pela Corsan. No entanto, existem também sistemas independentes de captação da água como poços unifamiliares ou pequenos poços coletivos, contudo, estes poços não apresentam 
registro e nem licença, como pode ser observado durante o campo. Maior parte das casas não possui rede de esgoto e estes são descartados diretamente no solo ou em corpos de água, ou mesmo quando existe rede de esgoto, este não é tratado adequadamente e disposto diretamente no mar, como podemos observar na Figura 3.

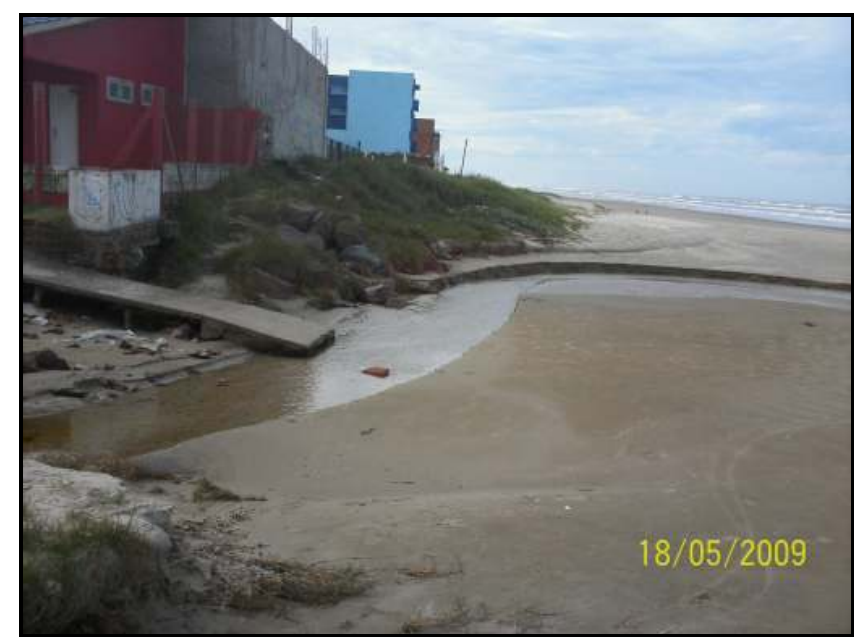

Figura 3: Esgoto a céu aberto (Pinhal/RS)

Foto: Lissner, J. B.

Outro registro de despejos de esgotos doméstico diretamente no mar pode ser visto na Figura 4. Ao fundo podemos observar construções de residenciais de alto padrão, que vem se expandindo cada vez mais no Litoral Norte, como no caso de Xangrilá - RS. Os maiores problemas ocasionados pela expansão da urbanização é o desmatamento dos ecossistemas locais que geralmente são muito frágeis e a falta de tratamento dos esgotos produzidos.

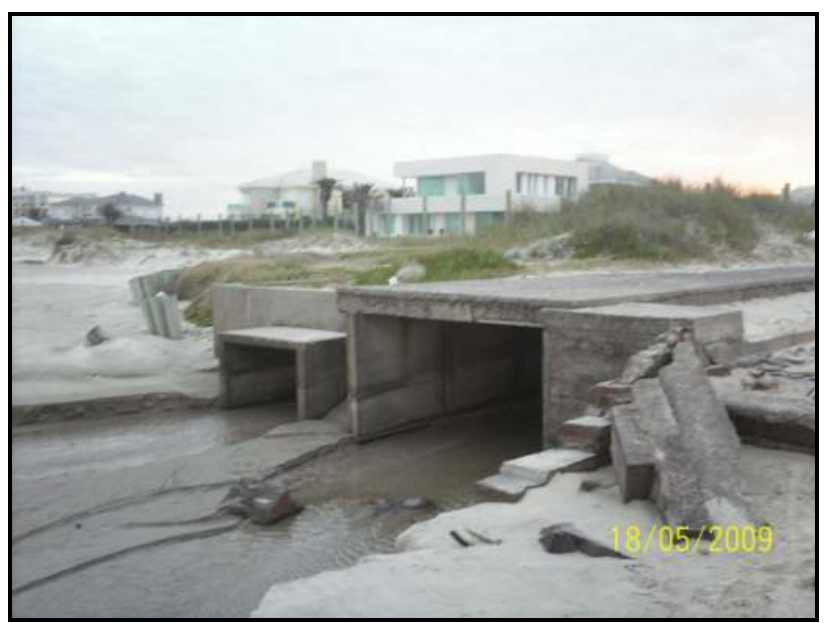

Figura 4: Expansão dos condomínios e esgotos Foto: Lissner, J. B. 
Na Figura 5 podemos observar a intensa ocupação e expansão da zona urbana ao redor do rio Tramandaí. As altas concentrações de coliformes fecais encontradas nas águas deste estuário provavelmente são oriundas dos esgotos cloacais dos municípios de Tramandaí e Imbé que não são tratados adequadamente e despejados diretamente na água.

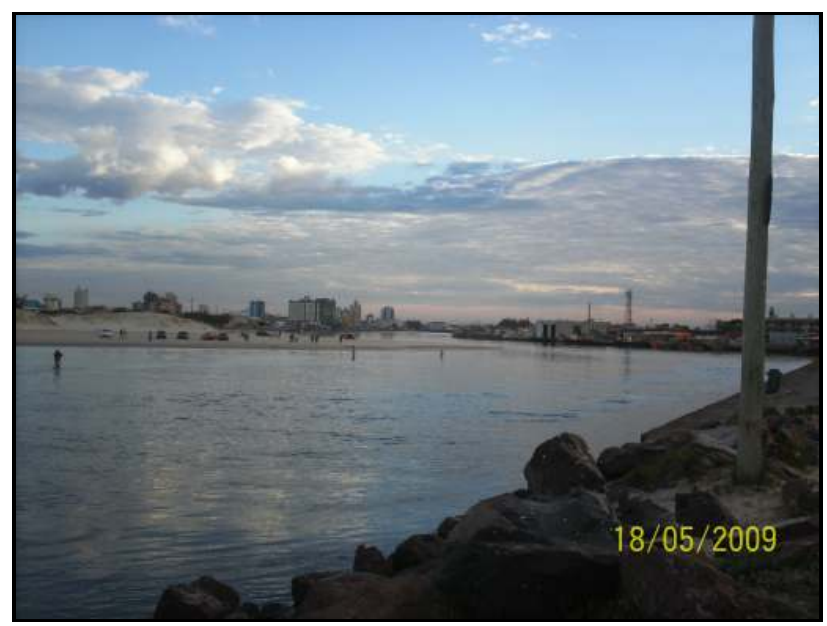

Figura 5: Ocupação em torno do estuário do Tramandaí Foto: Lissner, J. B.

$\mathrm{Na}$ figura 6 podemos ver o caso do rio Mampituba que apresenta problemas com matéria orgânica (DBO) e de coliformes fecais devido aos esgotos cloacais oriundos das áreas urbanas à montante da rodovia BR-101 nos municípios de Praia Grande e Torres na foz do rio. 


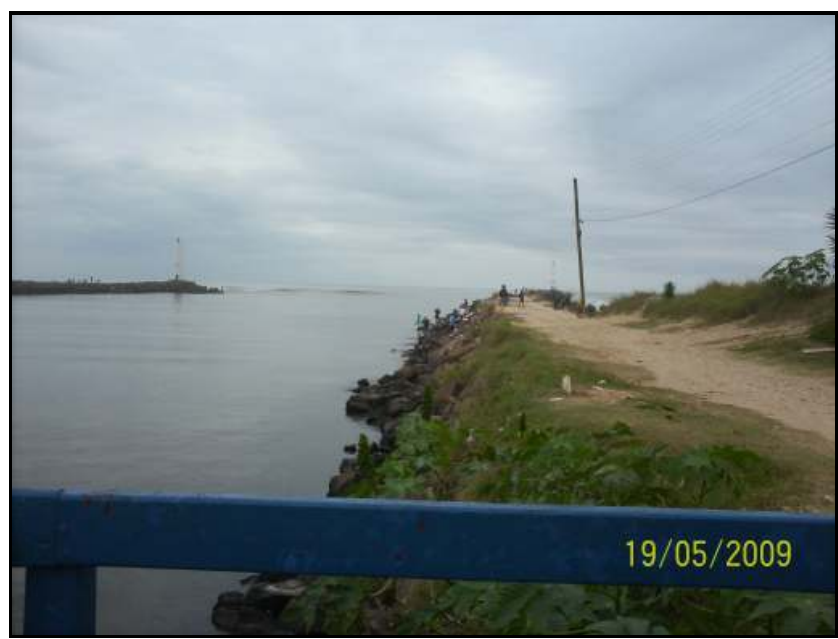

Figura 6: Grande concentração de DBO na foz do Mampituba Foto: Lissner, J. B.

A rede de abastecimento de água e rede de esgoto dos municípios do Litoral Norte é muito precária, no município de Maquiné, apenas $20 \%$ da população que reside na sede do município possui abastecimento de água. Em relação a rede de esgoto os índices são ainda mais baixos. Os dados do Censo Demográfico de 2000, realizado pelo IBGE, apontam que a forma de escoadouro de esgoto predominante na região é a fossa séptica, como podemos observar na tabela 2:

\begin{tabular}{l|c}
\hline Tipo de escoadouro & \% das residências \\
\hline Fossa séptica & $48,2 \%$ \\
\hline Fossa rudimentar & $33 \%$ \\
\hline Rede geral de esgoto & $13,2 \%$ \\
\hline Vala & $2,3 \%$ \\
\hline Não possuem banheiro & $2 \%$ \\
\hline Rios, lagos e mar & $0,4 \%$ \\
\hline Outro sistema & $0,9 \%$ \\
\hline
\end{tabular}

Tabela 2 - Estrutura do saneamento básico da região Org.: Lissner, J. B. (2009)

Conforme observamos na tabela 2, os esgotos em sua maioria não recebem tratamento adequado e acabam sendo despejados inadequadamente no meio ambiente atingindo os recursos hídricos, o que contraria as leis e padrões de lançamento de efluentes. Os tipos de escoadouros utilizados são rudimentares, sendo que algumas moradias não possuem nenhum tipo de banheiro e outros apenas desviam os efluentes diretamente para os rios, lagos e mar. 
No município de Maquiné não existe coleta nem tratamento de esgoto, caso comum na maioria dos municípios do Litoral Norte, pois estes não investem em infraestrutura para o tratamento dos esgotos por se tratarem na maioria das vezes de pequenos centros urbanos ou apenas cidades destinadas ao veraneio, sendo assim, são lançados nos corpos de água e no solo toneladas de carga poluidora orgânica proveniente de esgoto doméstico, sendo que esta quantidade quadruplica durante os meses de veraneio (dezembro, janeiro e fevereiro).

A inexistência de saneamento básico e fornecimento de água potável no meio rural do Litoral Norte obrigam a população residente a consumir água de vertentes ou diretamente do rio sem tratamento prévio, no entanto, estas águas podem estar contaminadas por agrotóxicos ou por esgotos.

\section{Gestão integrada dos Recursos Hídricos}

Conforme Gruber et al (2003) a Zona Costeira pode ser considerada uma região de contrastes devido a diversidade de usos do solo, constituindo-se de um desafio para o exercício de diferentes estratégias de gestão.

Os municípios têm um papel fundamental na gestão dos recursos hídricos, pois estes deverão estabelecer diretrizes regionais de uso dos recursos e aplicar as diretrizes em nível municipal, através da restrição e potencialidades de cada município, definido os usos permitidos e proibidos.

Contudo, a implementação das diretrizes deverá contar com a mobilização social e da cooperação entre os governos estaduais e municipais e a intervenção do município diretamente ou através de mobilização social é o foco principal das ações.

O município dispõe de instrumentos importantes como planos diretores, códigos e legislação ambiental para efetivar as estratégias municipais, conforme Fepam (2000). Assim, é de fundamental importância garantir que as estratégias sejam postas em prática, utilizando os instrumentos de forma efetiva e contando com a ajuda de todos os atores sociais da localidade. Também é importante a implantação dos planos de bacias.

Os municípios possuem diversos instrumentos para a gestão dos recursos hídricos, mas estes devem ser planejados e executados conforme os interesses prioritários dentro da bacia hidrográfica de forma conjunta que integre os municípios abrangidos por toda a bacia e pela comunidade local. Deverá ser formado também um comitê de gerenciamento da bacia hidrográfica para a elaboração e execução dos planos de gerenciamento que abranja toda a bacia hidrográfica. 
Conforme o Código Estadual do Meio Ambiente (Fepam, 2000) dentro dos planos e ações o município deve zelar pelo resguardo das águas para uso prioritário, como abastecimento da população; e também não deverá admitir o lançamento de efluentes nas lagoas mesmo que tratados, mantendo ou melhorando a qualidade das águas.

A participação das comunidades locais através de discussões juntamente com os órgãos públicos é fundamental para definir as estratégias quanto ao padrão futuro de ocupação da região e deverá orientar a execução da gestão da costa e garantir as condições de sustentabilidade e desenvolvimento. Esse processo de participação das comunidades integra a dinâmica das configurações física e natural com a dinâmica socioeconômica.

Conforme o Código Estadual do Meio Ambiente (Fepam, 2000) prevê que o gerenciamento costeiro deve ser realizado através de planejamento e gerenciamento integrado, descentralizado e participativo para as atividades antrópicas na zona costeira, assim como compatibilizar a utilização humana com a dinâmica dos ecossistemas para assegurar a melhoria da qualidade de vida e o equilíbrio ambiental. Além disso, deve promover e incentivar a elaboração de planos municipais de acordo com os princípios do gerenciamento costeiro compatibilizando as políticas e planos setoriais de desenvolvimento para a zona costeira com os princípios da Política Estadual do Meio Ambiente. Para dar inicio ao gerenciamento costeiro devem-se seguir as etapas de zoneamento ecológico e econômico, monitoramento, sistemas de informações, planos de gestão e licenciamento ambiental.

\section{Conclusão}

A gestão adequada dos recursos hídricos é essencial para a preservação do meio ambiente, no entanto, a gestão esbarra em diversos processos e atores que dificultam o planejamento e a ação. Como foi visto, a legislação vigente é bastante complexa e completa, e regulamenta o uso e utilização dos recursos hídricos, no entanto, não é seguido pela maioria dos municípios que compõem o Litoral Norte, o que pode ser comprovado pelos problemas observados durante o campo e pelos dados do IBGE apresentados no trabalho referente ao saneamento básico da região.

Conforme a classificação da qualidade das águas, as classes 1 e 2 (maior parte das águas do Litoral Norte) possuem seus fins de uso determinados, como para o consumo humano e recreação de contato primário, em nenhum momento é previsto a utilização destas águas para o despejo de esgotos tanto domésticos quanto industriais, mesmo assim observamos a ocorrência de despejos especialmente próximos aos centros urbanos. Caso seja necessária a utilização do corpo de água para o transporte e afastamento de esgotos sanitários 
este será permitido mediante licenciamento e tratamento adequado antes de seu lançamento. Conforme os dados obtidos em relação ao estado de contaminação das águas do Litoral Norte realizados pela Fepam, estas já se encontram bastante afetadas pelos despejos de esgotos oriundos dos centros urbanos, no entanto, se não houver um planejamento para a conservação das águas e um tratamento adequado e eficaz, em breve a qualidade das águas poderá alcançar índices de classificação ainda mais baixos.

O que podemos observar na região do Litoral Norte do estado é um rápido crescimento urbano sem planejamento e a falta de gestão dos recursos hídricos costeiros, tanto a nível municipal quanto em nível de bacia hidrográfica. Uma vez que a legislação dispõe e regulamenta o uso e utilização dos recursos hídricos de forma bastante completa, o problema não está na regulamentação e sim na gestão e preocupação da preservação do meio ambiente por parte dos agentes municipais.

Desta forma, para que ocorra uma gestão adequada dos recursos hídricos é necessário desenvolver primeiramente a consciência de toda a comunidade local da importância da preservação do meio ambiente, difícil missão esta que deve ser concretizada pela formação de comitês de gerenciamento que discuta as prioridades daquela bacia hidrográfica de forma integrada incluindo todos os municípios correspondentes, para que a gestão se torne completa, como no caso dos rios e lagoas do Litoral Norte que devem ser gerenciadas de forma integrada por todos os municípios que compõe a região.

\section{Referências}

BRAGA, B. et al. Introdução à engenharia ambiental: o desafio do desenvolvimento sustentável. 2 ed. São Paulo: Pearson Prentice Hall, 2005. 318 p.

CUNHA, S. B. da; GUERRA, A. J. T. A questão ambiental: diferentes abordagens. 3 ed. Rio de Janeiro: Bertrand Brasil, 2007. 248p.

FEPAM. Código Estadual do Meio Ambiente. Estado do Rio Grande do Sul, Brasil, 2000. FEPAM. Diretrizes ambientais para o desenvolvimento dos municípios do Litoral Norte. In: Cadernos de planejamento e gestão ambiental - $\mathrm{N}^{\circ} 1$. Brasil, RS, 2000. 
GRUBER, N. L. S.; BARBOZA, E. G.; NICOLODI, J. L. Geografia dos sistemas costeiros e oceanográficos: subsídios para a gestão integrada da zona costeira. In: Gravel. n. 1, pp. 81$89,2003$.

GUERRERO, E.; De KEIZER, O.; CÓRDOBA, R. La aplicación del enfoque ecossistémico en la gestión de los Recursos Hídricos. Union Mundial para la Naturaleza (UICN), Quito, Ecuador. 2006. 78 p.

PEREIRA, R.; SHÄFER, A. E. et al. Aplicabilidade de métodos de Sensoriamento Remoto na avaliação e monitoramento do estado trófico de lagoas costeiras do Rio Grande do Sul (RS). In: Simpósio Brasileiro de Sensoriamento Remoto. Anais XIII, INPE, p. 3513-3520. 2007. Resoluções do Conselho Nacional de Meio Ambiente - CONAMA. Resolução No 357 de 17 de março de 2005.

VILLWOCK, J. A.; TOMAZELLI, L. J. Planície Costeira do Rio Grande do Sul: gênese e paisagem atual. In: Biodiversidade: regiões da Lagoa do Casamento e dos Butiazais de Tapes, Planície Costeira do Rio Grande do Sul. Brasília: Ministério do Meio Ambiente, 2007. p. 20-33. 